\title{
Desempenho, sanidade animal e qualidade de filés de tilápias alimentadas com ração suplementada com biomassa bacteriana
}

\author{
[Performance, animal health and fillets quality of tilapia fed diets \\ supplemented with bacterial biomass]
}

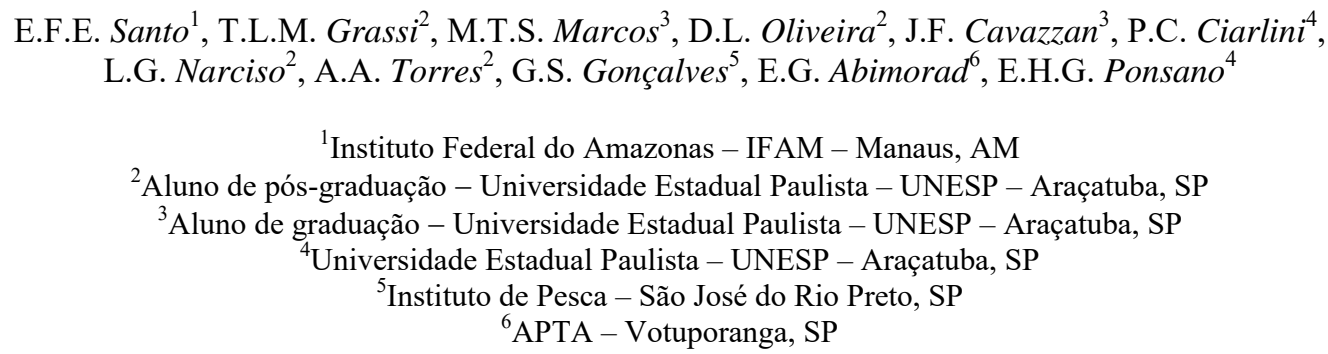

\section{RESUMO}

A aquicultura moderna é um dos setores de produção de alimentos que mais cresce no mundo. A tilápia, além de possuir grandes vantagens produtivas, origina produtos com grande aceitação pelo mercado. Em sua nutrição, podem ser utilizados aditivos com finalidades zootécnicas, pigmentantes ou antioxidantes. Este estudo objetivou avaliar o efeito da suplementação da dieta de tilápias com biomassa de Rubrivivax gelatinosus sobre o desempenho zootécnico e a saúde dos animais (histologia e hematologia) e sobre as características de qualidade dos filés ( $\mathrm{pH}$, composição químico-bromatológica, cor e rancidez). $\mathrm{O}$ experimento contou com seis tratamentos, compostos de um grupo controle, sem aditivos, um grupo contendo pigmentante comercial e quatro grupos com a biomassa nas concentrações de 175, 350, 700 e $1400 \mathrm{mg} / \mathrm{kg}$. Peixes pesando $21,42 \pm 5,65 \mathrm{~g}$ foram criados por 74 dias em sistema com recirculação de água e, posteriormente, foram abatidos para a realização das análises. Não foram encontradas diferenças para os resultados das análises de desempenho, histológicas e hematológicas. Os filés dos grupos alimentados com os aditivos apresentaram menor umidade que o grupo controle, e os filés dos grupos alimentados com biomassa apresentaram as maiores teores proteicos. Não houve diferenças entre os tratamentos para os valores de $\mathrm{pH}$, lipídeos e cinzas. Quanto à cor dos filés, todos os tratamentos com aditivos aumentaram a intensidade de vermelho. Em todos os tratamentos, a rancidez dos filés foi crescente durante o armazenamento, embora em menores valores nos filés dos grupos tratados com as maiores concentrações de biomassa. A biomassa de $R$. gelatinosus não promoveu alterações no desempenho nem na saúde animal e mostrou-se capaz de melhorar os aspectos de qualidade e conservação dos filés.

Palavras-chave: antioxidantes, cor, indústria pesqueira, pigmentos biológicos, Rubrivivax gelatinosus

\begin{abstract}
Modern aquaculture is one of the fastest growing food sectors in the world. Beyond having productivity advantages, tilapia fish yields products with great market acceptance. For its nutrition, additives aiming at increasing zootechnical, pigmenting or antioxidant features may be used. This study aimed to evaluate the effect of the supplementation of tilapia diets with Rubrivivax gelatinosus biomass on the performance and the health of animals (histology and hematology), and on the quality of fillets ( $\mathrm{pH}$, proximate composition, color and rancidity). The experiment comprised six treatments, made of a control group with no additives, a group containing commercial pigments and four groups with biomass at 175, 350, 700 and $1400 \mathrm{mg} / \mathrm{kg}$. Fish weighing 21.42 $\pm 5.65 \mathrm{~g}$ were reared for 74 days in a system with water recirculation and slaughtered for analyzes. No differences were detected for performance, histological
\end{abstract}

Recebido em 11 de setembro de 2014

Aceito em 3 de dezembro de 2015

E-mail: edson_fes@hotmail.com 
and hematological analyzes. Fillets of the groups fed additives had lower moisture content than the control group while the fillets of the groups fed the biomass had the highest protein percentages. No differences were detected among treatments for $\mathrm{pH}$, lipids and ash values. Regarding to the color of the fillets, all treatments with additives increased redness. For all treatments, rancidity in the fillets increased during storage, although the groups treated with the highest biomass concentrations had the lowest values. R. gelatinosus biomass did not change performance and animal health, and proved to be capable of improving fillets quality features and conservation.

Keywords: antioxidants, color, fishing industry, biological pigments, Rubrivivax gelatinosus

\section{INTRODUÇ̃̃O}

Entre os setores de alimentos de origem animal, a produção aquícola é a que mais cresce mundialmente e, na próxima década, deve ultrapassar a produção de bovinos, suínos e frangos. Além de representar renda para parte da população mundial, o pescado constitui importante fonte de nutrientes, principalmente proteica (Food and Agriculture Organization, 2014). Devido aos recursos hídricos disponíveis, ao clima favorável, à mão de obra relativamente barata e crescente mercado interno, o Brasil insere-se no contexto do aumento da produção de pescados (Silva et al., 2012). A aquicultura brasileira, apoiada em tilápias e algumas espécies nativas (pacu e pintado), é a segunda maior da América do Sul (Sussel, 2013).

A tilápia (Oreochromis niloticus) é uma espécie exótica e, no Brasil, sua criação destaca-se pela disponibilidade de alevinos, pelo domínio das técnicas reprodutivas, pela capacidade de aclimatação aos diferentes ambientes de criação, pelos índices zootécnicos adequados e pela aceitação de sua carne pelo mercado consumidor (Araújo, 2009). Na nutrição animal, podem ser utilizados aditivos, inclusive de origem bacteriana, para melhorar o desempenho animal e para pigmentar ou atuar como antioxidantes nos produtos finais (Valduga et al., 2009). No entanto, quando se utilizam aditivos na criação, é necessário verificar a manutenção da saúde animal, já que esta reflete diretamente sobre os índices zootécnicos e a qualidade dos produtos (Santos et al., 2009).

Rubrivivax gelatinosus é uma bactéria fototrófica natural de ambientes aquáticos e de efluentes (Sasikala et al., 1995) que, além de diminuir a carga orgânica, produz biomassa que contém aminoácidos essenciais, lipídeos, vitaminas e carotenoides. Esse produto pode ser utilizado como aditivo em ração animal, objetivando-se fins zootécnicos, pigmentantes ou antioxidantes (Kantachote et al., 2005; Santo et al., 2013).

$\mathrm{Na}$ produção animal intensiva, os produtos, sejam ovos, frangos ou peixes, não apresentam as mesmas cores quando comparados aos originados de animais criados em seu ambiente natural. Na natureza, os peixes se alimentam de pequenos crustáceos, plantas e algas que fornecem os pigmentos carotenoides, havendo deposição na carcaça. Dessa forma, justifica-se a adição dessas substâncias para aumentar a qualidade dos produtos finais e a aceitação do mercado consumidor (Almeida Júnior et al., 2012). As características organolépticas do produto final determinam a aceitabilidade do consumidor. Entre elas, a cor é um atributo de extrema importância, pois é um indicador de alterações químicas e bioquímicas possíveis de ocorrer durante $\mathrm{o}$ processamento $\mathrm{e} \quad \mathrm{o}$ armazenamento (Ribeiro et al., 2007). Essas alterações também acarretam a deterioração do pescado, sendo a oxidação lipídica um dos mais importantes processos de degradação por gerar sabores e odores desagradáveis nos produtos (Larosa, 2011), a qual pode ser minimizada pela atuação de substâncias com propriedades antioxidantes, tais como as apresentadas por alguns carotenoides.

Este estudo teve como objetivo avaliar o efeito da suplementação da ração de tilápias com biomassa de $R$. gelatinosus sobre o desempenho zootécnico e a saúde dos animais (histologia e hematologia) e sobre as características de qualidade dos filés obtidos $(\mathrm{pH}$, composição químico-bromatológica, cor e rancidez).

\section{MATERIAL E MÉTODOS}

A bactéria $R$. gelatinosus utilizada no experimento foi isolada de efluente de abatedouro avícola, e a cultura estoque foi reativada conforme descrito em Ponsano et al. 
(2002). O cultivo para a produção da biomassa de $R$. gelatinosus foi realizado em efluente de indústria e processamento de pescado (GeneSeas Aquacultura, Promissão/SP), conforme procedimentos descritos em Santo et al. (2013). A biomassa continha aproximadamente $55 \%$ de proteinas, $12 \%$ de lipídeos, $4 \%$ de sais minerais e $0,3 \%$ de carotenoides, e foi mantida refrigerada e ao abrigo da luz e do ar, até seu uso.

A criação dos animais foi conduzida no Setor Experimental de Zootecnia da Faculdade de Medicina Veterinária de Araçatuba da Unesp, em sistema fechado de recirculação de água (aprovação da Comissão de Ética: processo FOA $\mathrm{n}^{\mathrm{o}}$ 2013-01329). Esse sistema era composto de 24 caixas d'água, com capacidade de $1000 \mathrm{~L}$, decantador, caixas d'água para tratamento biológico e para aquecimento da água, soprador de oxigênio e bomba hidráulica. Anteriormente à realização do experimento, animais teste foram introduzidos no sistema para colonização e maturação do filtro biológico, por um período de 15 dias. Para o experimento, foram utilizados
1100 juvenis de tilápias sexualmente revertidos, com peso médio de $21,42 \pm 5,65 \mathrm{~g}$, provenientes de empresa de criação e reprodução localizada no município de Mirassol/SP. A adaptação e a aclimatação dos animais foram realizadas por um período de 15 dias, juntamente com o monitoramento dos parâmetros de água, para a avaliação do sistema e da eficácia do tratamento biológico. Nesse período, os animais foram alimentados com uma dieta base.

O delineamento experimental utilizado foi inteiramente ao acaso, com seis tratamentos e quatro repetições, totalizando 24 tanques, dentro dos quais foram divididos 960 peixes, resultando em 40 peixes por caixa. Os tratamentos foram constituídos de um grupo controle basal (T1), recebendo apenas uma dieta base, um grupo controle positivo (T2), recebendo pigmentante comercial sintético Carophyll Pink (astaxantina $10 \%$, DSM) junto à dieta base, e de quatro grupos (T3, T4, T5 e T6), recebendo diferentes concentrações da biomassa de $R$. gelatinosus como aditivo (Tab. 1).

Tabela 1. Tratamentos do experimento com tilápias e concentrações de aditivo

\begin{tabular}{cc}
\hline Tratamento & Dieta alimentar \\
\hline T1 & Dieta base \\
T2 & Dieta base + Carophyll Pink $(350 \mathrm{mg} / \mathrm{kg})$ \\
T3 & Dieta base + biomassa de $R$. gelatinosus $(175 \mathrm{mg} / \mathrm{kg})$ \\
T4 & Dieta base + biomassa de $R$. gelatinosus $(350 \mathrm{mg} / \mathrm{kg})$ \\
T5 & Dieta base + biomassa de $R$. gelatinosus $(700 \mathrm{mg} / \mathrm{kg})$ \\
T6 & Dieta base + biomassa de $R$. gelatinosus $(1400 \mathrm{mg} / \mathrm{kg})$ \\
\hline
\end{tabular}

Foi utilizada uma ração experimental extrusada (Tab. 2), com pellets de 2-4mm, formulada pelo programa Optimal Formula 2000, de acordo com valores de referência das Tabelas Brasileiras para a Nutrição de Tilápias (Furuya et al., 2010). A adição dos ingredientes pigmentantes à ração foi efetuada, em intervalos periódicos, em misturador de baixa rotação, com prévia mistura dos pigmentos em óleo de soja dentro das quantidades estabelecidas na formulação da ração. $\mathrm{O}$ arraçoamento foi realizado em quatro vezes diárias, durante o período do experimento (74 dias). A limpeza do sistema e as análises de qualidade de água $(\mathrm{pH}$, temperatura, oxigênio dissolvido, cloro, amônia tóxica e nitrito) foram realizadas de duas a três vezes por semana.

Ao final do período de criação, foram coletados os dados para as análises de desempenho e amostras para as avaliações hematológica, histológica e de qualidade dos filés.

O desempenho zootécnico foi determinado pelas medidas peso final, ganho de peso, consumo de ração e conversão alimentar aparente. Para o manejo e a pesagem dos peixes, foi utilizado o óleo de cravo-da-índia, diluído em água na concentração de $75 \mathrm{mg} / \mathrm{L}$, visando promover a sedação. 
Tabela 2. Rações experimentais e composição centesimal das dietas para tilápia-do-nilo com suplementação de Carophyll Pink e biomassa de R. gelatinosus ${ }^{1}$

\begin{tabular}{|c|c|c|c|c|c|c|}
\hline \multirow{3}{*}{ Ingredientes } & \multicolumn{6}{|c|}{ Tratamento [Aditivo pigmentante $(\%)$ ] } \\
\hline & \multirow[b]{2}{*}{$\mathrm{T} 1$} & \multirow{2}{*}{$\begin{array}{c}\mathrm{T} 2 \\
\text { (Carophyll } \\
\text { Pink) } \\
\end{array}$} & T3 & $\mathrm{T} 4$ & T5 & T6 \\
\hline & & & \multicolumn{4}{|c|}{ (Biomassa de R. gelatinosus) } \\
\hline Milho moído & 6,42 & 6,42 & 6,42 & 6,41 & 6,40 & 6,38 \\
\hline Farinha de vísceras de aves & 8,00 & 8,00 & 8,00 & 8,00 & 8,00 & 8,00 \\
\hline Farelo de soja & 45,00 & 45,00 & 45,00 & 45,00 & 45,00 & 45,00 \\
\hline Farelo de trigo & 17,00 & 17,00 & 17,00 & 17,00 & 17,00 & 17,00 \\
\hline Quirera de arroz & 7,60 & 7,60 & 7,60 & 7,60 & 7,60 & 7,60 \\
\hline Farelo de arroz gordo & 5,00 & 5,00 & 5,00 & 5,00 & 5,00 & 5,00 \\
\hline Farinha de carne & 6,00 & 6,00 & 6,00 & 6,00 & 6,00 & 6,00 \\
\hline Aglutinante (Binder) & 0,10 & 0,10 & 0,10 & 0,10 & 0,10 & 0,10 \\
\hline Sal & 0,30 & 0,30 & 0,30 & 0,30 & 0,30 & 0,30 \\
\hline Fosfato bicálcico & 1,32 & 1,32 & 1,32 & 1,32 & 1,32 & 1,32 \\
\hline Óleo de soja & 2,13 & 2,13 & 2,13 & 2,13 & 2,13 & 2,13 \\
\hline Cloreto de colina $70 \%$ & 0,20 & 0,20 & 0,20 & 0,20 & 0,20 & 0,20 \\
\hline DL-Metionina & 0,22 & 0,22 & 0,22 & 0,22 & 0,22 & 0,22 \\
\hline Antifúngico (Fylax) & 0,20 & 0,20 & 0,20 & 0,20 & 0,20 & 0,20 \\
\hline Suplemento mineral/ vitamínico ${ }^{2}$ & 0,50 & 0,50 & 0,50 & 0,50 & 0,50 & 0,50 \\
\hline Aditivo pigmentante & 0,00 & 0,035 & 0,0175 & 0,035 & 0,070 & 0,140 \\
\hline \multicolumn{7}{|c|}{ Nutrientes/Energia - valores calculados } \\
\hline Energia digestível (kcal/kg) & 3000 & 3000 & 3000 & 3000 & 3000 & 3000 \\
\hline Proteína digestível (\%) & 27,20 & 27,20 & 27,20 & 27,20 & 27,20 & 27,20 \\
\hline Proteína bruta $(\%)$ & 32,00 & 32,00 & 32,00 & 32,00 & 32,00 & 32,00 \\
\hline Extrato etéreo $(\%)$ & 6,00 & 6,00 & 6,00 & 6,00 & 6,00 & 6,00 \\
\hline Fibra bruta $(\%)$ & 4,50 & 4,50 & 4,50 & 4,50 & 4,50 & 4,50 \\
\hline Matéria mineral (\%) & 9,00 & 9,00 & 9,00 & 9,00 & 9,00 & 9,00 \\
\hline Cálcio total (\%) & 1,63 & 1,63 & 1,63 & 1,63 & 1,63 & 1,63 \\
\hline Fósforo total (\%) & 1,30 & 1,30 & 1,30 & 1,30 & 1,30 & 1,30 \\
\hline Amido (\%) & 22,00 & 22,00 & 22,00 & 22,00 & 22,00 & 22,00 \\
\hline Fósforo disponível (\%) & 0,70 & 0,70 & 0,70 & 0,70 & 0,70 & 0,70 \\
\hline Lisina $(\%)$ & 2,00 & 2,00 & 2,00 & 2,00 & 2,00 & 2,00 \\
\hline Treonina $(\%)$ & 1,20 & 1,20 & 1,20 & 1,20 & 1,20 & 1,20 \\
\hline Triptofano $(\%)$ & 0,35 & 0,35 & 0,35 & 0,35 & 0,35 & 0,35 \\
\hline Metionina (\%) & 0,65 & 0,65 & 0,65 & 0,65 & 0,65 & 0,65 \\
\hline Vitamina C $(\mathrm{mg} / \mathrm{kg})$ & 300 & 300 & 300 & 300 & 300 & 300 \\
\hline Cálcio/Fósforo total & 1,50 & 1,50 & 1,50 & 1,50 & 1,50 & 1,50 \\
\hline
\end{tabular}

${ }^{1}$ Baseados nos valores de composição dos alimentos e nutrição de tilápias, de Furuya et al. (2010); ${ }^{2}$ níveis de garantia por quilograma do produto: vit. A, 2.400.000UI; vit. D3, 600.000UI; vit. E, 30.000mg; vit. K3, 3.000mg; vit. B1, $4.000 \mathrm{mg}$; vit. B2, 4.000mg; vit. B6, 3.500mg; vit. B12, $8.000 \mathrm{mg}$; vit. C, 60.000mg; ác. nicotínico, 20.000mg; pantotenato $\mathrm{Ca}, 10.000 \mathrm{mg}$; biotina, $200 \mathrm{mg}$; ác. fólico, $1.200 \mathrm{mg}$; cobre, $3.500 \mathrm{mg}$; ferro, 20.000mg; manganês, $10.000 \mathrm{mg}$; zinco, $24.000 \mathrm{mg}$; cálcio, $160 \mathrm{mg}$; sódio, $100 \mathrm{mg}$; cobalto, $80 \mathrm{mg}$; inositol, $25.000 \mathrm{mg}$; cloreto de colina, $100.000 \mathrm{mg}$.

Para a avaliação hematológica, dois animais de cada caixa (oito peixes/tratamento) foram anestesiados em solução aquosa de benzocaína $(0,1 \mathrm{~g} / \mathrm{L})$ e, então, puncionados nos vasos caudais. $\mathrm{O}$ hemograma total foi composto pelo eritrograma e pelo leucograma, processados conforme o protocolo padrão de rotina. Para a avaliação histológica, realizada com o objetivo de detectar lesões, os animais foram anestesiados em plano profundo com óleo de cravo-da-índia (180mg/L por $10 \mathrm{~min})$, seguindo-se a eutanásia por secção medular. A necropsia foi realizada em oito animais por tratamento, para a remoção de fígado, baço e intestino, sendo os fragmentos acondicionados em solução de formaldeído a $10 \%$ tamponado durante 24 horas e, depois, 
transferidos para solução de álcool a 70\% para posterior inclusão em parafina e processamento de rotina para coloração de hematoxilina-eosina. A leitura das lâminas foi realizada em microscópio de luz.

Para as análises de qualidade e caracterização dos filés, oito animais por tratamento foram insensibilizados em água e gelo (1:2), sangrados na região branquial e filetados. Para a determinação do $\mathrm{pH}, 10 \mathrm{~g}$ das amostras dos filés foram homogeneizados em $100 \mathrm{~mL}$ de água destilada, e a leitura foi realizada com o medidor de $\mathrm{pH}$ digital microprocessado (Tecnal Tec-5). Para a análise de composição, foram realizadas as determinações de umidade (secagem a $105^{\circ} \mathrm{C}$, até a obtenção de peso constante), proteínas totais (método de micro-Kjehdahl), lipídeos totais (método de Folch) e cinzas (incineração a $550^{\circ} \mathrm{C}$ ). As análises foram realizadas em duplicata, seguindo as metodologias descritas em Folch et al. (1957) e Horwitz e Latimer Jr. (2006). A avaliação colorimétrica foi realizada nos filés esquerdos de 12 animais por tratamento. Foram realizadas três leituras consecutivas dos atributos $L$ (luminosidade), a (intensidade de vermelho) e $b$ (intensidade de amarelo), em três pontos, definidos como: ponto 1 (cranial), ponto 2 (medial) e ponto 3 (caudal), utilizando-se colorímetro portátil Mini Scan XE Plus, calibrado com padrões branco e preto. A rancidez dos filés foi determinada pelo valor das substâncias reativas ao ácido tiobarbitúrico
(TBARS) conforme metodologia descrita por Vyncke (1970). As análises foram realizadas antes do congelamento e aos 20, 40, 60 e 80 dias de armazenamento, realizado a $-22^{\circ} \mathrm{C}$ em filme plástico.

A análise estatística foi realizada mediante o uso do teste exato de Fisher para os resultados histológicos, e a análise de variância e o teste Student-Newman-Keuls para a comparação múltipla das médias dos demais dados. As análises foram realizadas com o programa SAS 9.3 (2011), utilizando nível de significância de $5 \%$.

\section{RESULTADOS E DISCUSSÃO}

Durante todo o período experimental, foi mantida a qualidade da água, e os parâmetros avaliados permaneceram dentro da faixa de conforto para a espécie, com valores médios de temperaturas de $26,74 \pm 0,30^{\circ} \mathrm{C}, \mathrm{pH} 7,26 \pm 0,05$, oxigênio dissolvido $2,99 \pm 0,20 \mathrm{mg} / \mathrm{L}$, amônia tóxica $0,004 \pm 0,0006 \mathrm{ppm}$, nitrito $0,78 \pm 0,10 \mathrm{ppm}$ e cloro $0,01 \pm 0,002 \mathrm{ppm}$.

A suplementação com os aditivos na ração não influenciou os parâmetros de desempenho zootécnico (Tab. 3), quando comparados ao uso da dieta base $(\mathrm{P}>0,05)$, e estiveram dentro da normalidade (Moraes et al., 2009). Em relação à mortalidade, apenas três animais de diferentes parcelas vieram a óbito durante o experimento.

Tabela 3. Médias e desvios-padrão dos resultados de peso final (PF), ganho de peso (GP), consumo de ração (CR) e conversão alimentar aparente (CAA) dos tratamentos

\begin{tabular}{lcccc}
\multicolumn{1}{c}{ Tratamento } & PF $(\mathrm{g})$ & GP $(\mathrm{g})$ & CR $(\mathrm{g})$ & CAA \\
\hline Controle & & & & \\
Carophyll 350mg/kg & $173,44 \pm 30,34$ & $152,50 \pm 27,80$ & $218,04 \pm 15,60$ & $1,45 \pm 0,16$ \\
Biomassa $175 \mathrm{mg} / \mathrm{kg}$ & $153,76 \pm 18,43$ & $134,31 \pm 15,58$ & $206,74 \pm 14,42$ & $1,54 \pm 0,10$ \\
Biomassa $350 \mathrm{mg} / \mathrm{kg}$ & $169,69 \pm 26,60$ & $143,12 \pm 24,62$ & $212,62 \pm 17,34$ & $1,50 \pm 0,15$ \\
Biomassa $700 \mathrm{mg} / \mathrm{kg}$ & $133,73 \pm 14,34$ & $113,91 \pm 20,51$ & $189,82 \pm 17,53$ & $1,68 \pm 0,18$ \\
Biomassa $1400 \mathrm{mg} / \mathrm{kg}$ & $136,38 \pm 21,03$ & $118,28 \pm 21,03$ & $194,19 \pm 11,50$ & $1,66 \pm 0,18$ \\
\hline
\end{tabular}

Os parâmetros hematológicos não diferiram entre os tratamentos $(\mathrm{P}>0,05)$ e se mantiveram dentro da normalidade (Tavares-Dias e Moraes, 2004). Esses dados demonstram que a biomassa não promoveu alterações na composição sanguínea e que os animais se mantiveram saudáveis durante o período experimental.

$\mathrm{Na}$ avaliação histológica comparativa, apesar de terem sido encontradas algumas alterações em órgãos de animais de diferentes tratamentos, não 
houve diferença significativa entre os fígados $(\mathrm{P}=0,1317)$, baços $(\mathrm{P}=0,5148)$ e intestinos $(\mathrm{P}=0,4079)$ avaliados. Esses dados indicam que o uso de aditivos pigmentantes não interferiu na morfologia dos órgãos de eleição para alterações patológicas.

$\mathrm{O}$ pH e a composição químico-bromatológica dos filés estão descritos na Tab. 4. Os filés dos grupos alimentados com a biomassa apresentaram maiores valores proteicos $(\mathrm{P}=0,0016)$ e menores porcentagens de umidade
$(\mathrm{P}=0,0003)$. Os valores proteicos levam a crer que a biomassa de $R$. gelatinosus possua algum princípio ativo que favoreça a absorção e a deposição de proteínas, fato que futuramente deverá ser estudado. A maior concentração proteica nos filés esclarece a consequente redução da umidade nos produtos, já que os constituintes orgânicos e inorgânicos são inversamente proporcionais à quantidade de água na carne. Para os demais parâmetros avaliados, $\mathrm{pH}$, lipídeos e cinzas, não foram encontradas diferenças significativas entre os tratamentos.

Tabela 4. Médias e desvios-padrão dos valores de pH e composição químico-bromatológica dos filés de tilápias, de acordo com o tratamento

\begin{tabular}{lccccc}
\multicolumn{1}{c}{ Tratamento } & $\mathrm{pH}$ & Umidade (\%) & Lipídeos (\%) & Proteína (\%) & Cinzas (\%) \\
\hline Controle & $6,36 \pm 0,08$ & $79,03 \pm 0,60 \mathrm{a}$ & $1,16 \pm 0,08$ & $18,20 \pm 0,48 \mathrm{~b}$ & $1,30 \pm 0,09$ \\
Carophyll 350mg/kg & $6,27 \pm 0,13$ & $77,86 \pm 0,46 \mathrm{~b}$ & $1,25 \pm 0,21$ & $18,43 \pm 0,82 \mathrm{~b}$ & $1,32 \pm 0,08$ \\
Biomassa $175 \mathrm{mg} / \mathrm{kg}$ & $6,31 \pm 0,05$ & $77,90 \pm 0,31 \mathrm{~b}$ & $1,30 \pm 0,37$ & $19,99 \pm 0,42 \mathrm{a}$ & $1,26 \pm 0,07$ \\
Biomassa 350mg/kg & $6,32 \pm 0,12$ & $77,29 \pm 0,47 \mathrm{~b}$ & $1,22 \pm 0,19$ & $19,45 \pm 0,46 \mathrm{a}$ & $1,34 \pm 0,08$ \\
Biomassa 700mg/kg & $6,24 \pm 0,03$ & $77,23 \pm 0,64 \mathrm{~b}$ & $1,38 \pm 0,16$ & $19,53 \pm 0,58 \mathrm{a}$ & $1,38 \pm 0,05$ \\
Biomassa $1400 \mathrm{mg} / \mathrm{kg}$ & $6,19 \pm 0,01$ & $77,25 \pm 0,29 \mathrm{~b}$ & $1,44 \pm 0,24$ & $19,76 \pm 0,67 \mathrm{a}$ & $1,44 \pm 0,24$ \\
\hline
\end{tabular}

Valores na coluna seguidos da mesma letra não diferem entre si segundo o teste SNK $(\mathrm{P}>0,05)$.

Os valores de $\mathrm{pH}$ encontrados neste experimento foram inferiores ao valor legal máximo preconizado pela legislação brasileira, que é de 6,8 para o pescado fresco (Brasil, 1952). Isso indica um correto manejo no abate, o que propiciou uma queda de $\mathrm{pH}$ apropriada para a conservação da carne. Santos (2013), ao avaliar o $\mathrm{pH}$ de filés de tilápias, resfriados e submetidos a diferentes métodos de abate, também encontrou valores inferiores a 6,8 . A composição dos filés de pescado pode variar com o sexo, a idade, a época de captura, o habitat e a dieta consumida, e os valores encontrados neste experimento estão de acordo com os apresentados por outros autores. Otani (2009), ao utilizar a vitamina E como antioxidante na dieta, identificou nos filés $78,69 \%$ de umidade, 0,97 a $1,11 \%$ de lipídeos, 18,98 a $19,37 \%$ de proteínas e 1,13 a $1,15 \%$ de cinzas. Druzian et al. (2012), quando usaram rações com diferentes formulações, verificaram os seguintes valores nos filés de tilápias: 78,52 a $80,63 \%$ de umidade, 0,98 a $1,08 \%$ de lipídeos, 18,50 a $19,07 \%$ de proteína e 1,07 a $1,18 \%$ de cinzas.
Os valores médios dos atributos de cor dos filés nos três pontos avaliados estão apresentados na Tab. 5. Os valores de $L$ e $b$ não diferiram em nenhum dos pontos $(\mathrm{P}>0,05)$, enquanto os tratamentos com aditivos pigmentantes apresentaram maiores valores de $a$, o que indica maior intensidade de vermelho. No ponto cranial, a intensidade de vermelho produzida pelas maiores concentrações da biomassa foi superior à produzida pelo aditivo pigmentante sintético Carophyll Pink.

Com a melhora da pigmentação, além de outras características apontadas neste estudo, os filés podem ser indicados como uma nova opção para o mercado de pescado, com possibilidade de agregação de valor, como ocorreu com a truta salmonada, produto com grande aceitação (Tabata, 2007). Os atributos de cor podem variar de acordo com o abate, a alimentação e o local de mensuração. Santos (2013) encontrou valores médios para $L$ de $54, a$ de 2 , e $b$ de 8 em filés de tilápias abatidas com água e gelo. Souza et al. (2005) compararam a qualidade de filés de tilápias in natura e defumados e encontraram 
valores para o produto in natura de 61,70 para o atributo $L,-0,74$ para $a$ e 10,17 para $b$. Oliveira (2009), ao adicionar licopeno na ração de tilápias para verificação de seus efeitos nos animais, constatou que esse pigmento não alterou a cor dos filés, quando comparados ao controle, obtendo valores de 54,88 para $L$, de 2,41 para $a$ e de 9,95 para $b$.

Tabela 5. Médias e desvios-padrão dos valores dos atributos da cor ( $L$ - luminosidade, $a$ - vermelho, $b$ amarelo) em três locais de mensuração nos filés de tilápias

\begin{tabular}{|c|c|c|c|c|}
\hline Local & Tratamento & $L$ & $A$ & $b$ \\
\hline \multirow{6}{*}{ Ponto cranial } & Controle & $51,34 \pm 1,24$ & $-0,23 \pm 0,13 d$ & $10,01 \pm 0,73$ \\
\hline & Carophyll 350mg/kg & $51,50 \pm 1,26$ & $0,20 \pm 0,19 \mathrm{c}$ & $10,21 \pm 0,97$ \\
\hline & Biomassa $^{1} 175 \mathrm{mg} / \mathrm{kg}$ & $52,91 \pm 1,84$ & $0,45 \pm 0,14 b$ & $10,58 \pm 1,53$ \\
\hline & Biomassa 350mg/kg & $51,69 \pm 1,40$ & $0,35 \pm 0,09 b c$ & $10,17 \pm 0,43$ \\
\hline & Biomassa $700 \mathrm{mg} / \mathrm{kg}$ & $51,77 \pm 1,74$ & $0,89 \pm 0,07 \mathrm{a}$ & $10,90 \pm 1,71$ \\
\hline & Biomassa $1400 \mathrm{mg} / \mathrm{kg}$ & $52,01 \pm 2,21$ & $0,53 \pm 0,14 \mathrm{~b}$ & $11,29 \pm 1,07$ \\
\hline \multirow{6}{*}{ Ponto medial } & Controle & $52,25 \pm 0,40$ & $1,21 \pm 0,26 \mathrm{c}$ & $10,96 \pm 0,77$ \\
\hline & Carophyll 350mg/kg & $51,83 \pm 2,34$ & $2,48 \pm 0,26 a b$ & $11,37 \pm 0,41$ \\
\hline & Biomassa $175 \mathrm{mg} / \mathrm{kg}$ & $51,85 \pm 0,53$ & $1,37 \pm 0,17 \mathrm{c}$ & $10,52 \pm 1,41$ \\
\hline & Biomassa $350 \mathrm{mg} / \mathrm{kg}$ & $50,68 \pm 1,46$ & $2,08 \pm 0,31 b$ & $10,87 \pm 0,19$ \\
\hline & Biomassa $700 \mathrm{mg} / \mathrm{kg}$ & $50,89 \pm 0,98$ & $2,66 \pm 0,31 \mathrm{a}$ & $12,01 \pm 2,21$ \\
\hline & Biomassa $1400 \mathrm{mg} / \mathrm{kg}$ & $50,18 \pm 1,80$ & $2,49 \pm 0,30 \mathrm{ab}$ & $11,88 \pm 0,85$ \\
\hline \multirow{6}{*}{ Ponto caudal } & Controle & $54,89 \pm 2,58$ & $2,99 \pm 0,37 b$ & $11,52 \pm 0,59$ \\
\hline & Carophyll 350mg/kg & $54,01 \pm 2,54$ & $4,58 \pm 0,38 \mathrm{a}$ & $12,00 \pm 0,60$ \\
\hline & Biomassa $175 \mathrm{mg} / \mathrm{kg}$ & $53,02 \pm 3,60$ & $4,01 \pm 0,34 \mathrm{a}$ & $11,83 \pm 1,10$ \\
\hline & Biomassa $350 \mathrm{mg} / \mathrm{kg}$ & $52,98 \pm 4,83$ & $4,08 \pm 0,39 a$ & $11,14 \pm 0,74$ \\
\hline & Biomassa $700 \mathrm{mg} / \mathrm{kg}$ & $55,07 \pm 1,63$ & $4,24 \pm 0,27 \mathrm{a}$ & $12,38 \pm 2,04$ \\
\hline & Biomassa $1400 \mathrm{mg} / \mathrm{kg}$ & $54,60 \pm 3,47$ & $4,63 \pm 0,25 \mathrm{a}$ & $12,97 \pm 1,55$ \\
\hline
\end{tabular}

Valores na coluna seguidos da mesma letra não diferem entre si segundo o teste $\mathrm{SNK}(\mathrm{P}>0,05)$. ${ }^{1}$ Biomassa de $R$. gelatinosus.

Para os mesmos tratamentos, os valores de TBARS, expressos em mg de malonaldeído (MA) $/ \mathrm{kg}$ de carne, mostraram-se crescentes durante o armazenamento, com estabilização a partir de 60 dias (Tab. 6). Ao se comparar a rancidez nos diferentes momentos, verificou-se que o uso da biomassa na ração foi efetivo em minimizar a reação já a partir de 20 dias de armazenamento. Os resultados mais significativos foram encontrados para as maiores concentrações do produto, diferindo, também, dos valores apresentados pelo grupo contendo Carophyll. O uso dos pigmentantes não interrompeu as reações oxidativas, porém amenizou essa ocorrência, contribuindo para a manutenção da qualidade dos filés.

A taxa de oxidação depende de inúmeros fatores, incluindo a composição de ácidos graxos e a concentração de agentes pró e antioxidantes que podem ser manipulados pela dieta (Fogaça e
Sant'ana, 2009). Ke et al. (1984), ao trabalharem com diversas espécies de pescado, sugeriram uma escala para TBARS, na qual consideram baixos os valores inferiores a $0,576 \mathrm{mg} \mathrm{MA} / \mathrm{kg}$, levemente rançosos os valores entre 0,648 e $1,44 \mathrm{mg} \mathrm{MA} / \mathrm{kg}$, e como inaceitáveis os valores superiores a $1,51 \mathrm{mg} \mathrm{MA} / \mathrm{kg}$.

Wang et al. (2006) utilizaram a astaxantina na alimentação de peixes e encontraram menor oxidação na musculatura desses animais, concluindo que esse carotenoide, além de possuir efeito pigmentante, possui função antioxidante nesses animais. Rodríguez et al. (2007) avaliaram alterações lipídicas em salmões alimentados com rações suplementadas com astaxantina e tocoferol, e identificaram menor rancidez no armazenamento. Otani (2009), ao utilizar a vitamina $\mathrm{E}$ na dieta de tilápias, verificou sua positiva ação na redução das taxas de oxidação lipídica nos filés durante 
armazenamento. Oliveira (2009), com o uso do licopeno na alimentação de tilápias, observou efeitos antioxidantes nos filés de animais submetidos a estresse. Kirschnik et al. (2013) avaliaram a CMS de tilápias e observaram que a lavagem e o uso de conservantes reduziram a rancidez dos produtos durante o armazenamento, apesar do gradual aumento, com valores de 0,15 a $0,7 \mathrm{mg} \mathrm{MA} / \mathrm{kg}$.

Tabela 6. Médias e desvios-padrão dos valores de TBARS (mg MA/kg) em filés de tilápias de acordo com o tratamento e o tempo de armazenamento sob congelamento ${ }^{1}$, sendo T1 - controle, T2 - Carophyll $350 \mathrm{mg} / \mathrm{kg}$, T3 - biomassa ${ }^{2} 175 \mathrm{mg} / \mathrm{kg}$, T4 - biomassa 350mg/kg, T5 - biomassa $700 \mathrm{mg} / \mathrm{kg}$ e T6 - biomassa $1400 \mathrm{mg} / \mathrm{kg}$

\begin{tabular}{ccccccc}
\hline \multirow{2}{*}{ Tratamento } & \multicolumn{5}{c}{ Dia } & P \\
\cline { 2 - 6 } & 0 & 20 & 40 & 60 & 80 & \\
\hline T1 & $0,071 \pm 0,025 \mathrm{D}$ & $0,343 \pm 0,048 \mathrm{Ca}$ & $0,647 \pm 0,090 \mathrm{Ba}$ & $0,799 \pm 0,046 \mathrm{Aa}$ & $0,807 \pm 0,028 \mathrm{Aa}$ & $<0,01^{3}$ \\
T2 & $0,052 \pm 0,022 \mathrm{D}$ & $0,331 \pm 0,084 \mathrm{Ca}$ & $0,454 \pm 0,049 \mathrm{Bb}$ & $0,579 \pm 0,049 \mathrm{Ab}$ & $0,596 \pm 0,124 \mathrm{Ab}$ & $<0,01^{4}$ \\
T3 & $0,040 \pm 0,002 \mathrm{D}$ & $0,192 \pm 0,062 \mathrm{Cb}$ & $0,484 \pm 0,076 \mathrm{Bb}$ & $0,596 \pm 0,055 \mathrm{Ab}$ & $0,604 \pm 0,034 \mathrm{Ab}$ & $<0,01^{5}$ \\
T4 & $0,046 \pm 0,022 \mathrm{C}$ & $0,155 \pm 0,028 \mathrm{Bb}$ & $0,378 \pm 0,048 \mathrm{Bbc}$ & $0,453 \pm 0,087 \mathrm{Ac}$ & $0,468 \pm 0,044 \mathrm{Ac}$ & $<0,01^{6}$ \\
T5 & $0,033 \pm 0,013 \mathrm{D}$ & $0,143 \pm 0,036 \mathrm{Cb}$ & $0,358 \pm 0,045 \mathrm{Bbc}$ & $0,448 \pm 0,032 \mathrm{Ac}$ & $0,453 \pm 0,036 \mathrm{Ac}$ & $<0,01^{7}$ \\
T6 & $0,033 \pm 0,009 \mathrm{D}$ & $0,124 \pm 0,034 \mathrm{Cb}$ & $0,317 \pm 0,069 \mathrm{Bc}$ & $0,444 \pm 0,061 \mathrm{Ac}$ & $0,459 \pm 0,039 \mathrm{Ac}$ & $<0,01^{8}$ \\
\hline
\end{tabular}

${ }^{1}$ Médias seguidas de mesma letra, maiúsculas (linha) e minúsculas (coluna), não diferem entre si pelo teste SNK $(\mathrm{P}>0,05) . \mathrm{X}=$ dias e $\mathrm{Y}=$ valores de TBARS. ${ }^{2}$ Biomassa de R. gelatinosus. ${ }^{3} \mathrm{y}=-0,0001 \mathrm{x}^{2}+0,0194 \mathrm{x}+0,051\left(\mathrm{r}^{2}=0,991\right)$; ${ }^{4} \mathrm{y}=0,00009 \mathrm{x}^{2}+0,0142 \mathrm{x}+0,0601 \quad\left(\mathrm{r}^{2}=0,994\right) ;{ }^{5} \mathrm{y}=0,0008 \mathrm{x}^{2}+0,0143 \mathrm{x}+0,010\left(\mathrm{r}^{2}=0,968\right) ;{ }^{6} \mathrm{y}=0,00006 \mathrm{x}^{2}+0,0105 \mathrm{x}+0,0242$ $\left(\mathrm{r}^{2}=0,967\right) ;{ }^{7} \mathrm{y}=-0,0006 \mathrm{x}^{2}+0,0105 \mathrm{x}+0,0108\left(\mathrm{r}^{2}=0,968\right) ;{ }^{8} \mathrm{y}=0,0004 \mathrm{x}^{2}+0,009 \mathrm{x}+0,0101\left(\mathrm{r}^{2}=0,966\right)$.

\section{CONCLUSÃO}

A biomassa de $R$. gelatinosus não promoveu alterações no desempenho e na saúde animal, sob os pontos de vista histológico e hematológico, e mostrou-se capaz de aumentar o teor proteico e a coloração vermelha dos filés, bem como diminuir a oxidação lipídica durante o armazenamento. Dessa forma, dentro das condições estudadas neste experimento, confirma-se a viabilidade do uso desse aditivo na alimentação de tilápias para incrementar a qualidade e a preservação da carne congelada.

\section{AGRADECIMENTOS}

Os autores agradecem à Fundação de Amparo à Pesquisa do Estado de São Paulo - Fapesp (processos 2011/01103-2 e 2011/50274-4), pela bolsa de estudos e pelo auxílio financeiro concedidos para a realização desta pesquisa, e à indústria GeneSeas Aquacultura Ltda., pelo fornecimento do efluente industrial.

\section{REFERÊNCIAS}

ALMEIDA JÚNIOR, G.A.; STRADIOTTI JÚNIOR, D.; SILVA, E.C.G. et al. O profissional de zootecnia no século XXI. 2012. Disponível em: <http://www.zootecnia.alegre. ufes.br/sites/zootecnia.alegre.ufes.br/files/field/fi le/Livro\%20Zootecnia $\% 20 \mathrm{em} \% 20$ recurso $\% 20 \mathrm{el}$ etr\%C3\%B4nico\%20\%20ebook.pdf\#page $=6>$. Acessado em: 22 maio 2014.

ARAUJO, D.M. Fontes de lipídeos poliinsaturados na nutrição e saúde da tilápia do nilo (Oreochromis niloticus). 2009. 80f. Tese (Doutorado em Zootecnia) - Faculdade de Medicina Veterinária e Zootecnia, Universidade Estadual Paulista, Botucatu, SP.

DRUZIAN, J.I.; MACHADO, B.A.S.; SOUZA, C.O. et al. Influência da dieta suplementada com óleo de soja na composição centesimal e perfil lipídico de tilápias do Nilo. Rev. Inst. Adolfo Lutz, v.71, p.85-92, 2012.

FOGAÇA, F.H.S.; SANT'ANA, L.S. Oxidação lipídica em peixes: mecanismo de ação e prevenção. Arch. Vet. Sci., v.14, p.117-127, 2009. 
FOLCH, J.; LEES, M.; SLOANNE, S.G.H. A simple method for the isolation and purification of total lipid from animal tissues. J. Biol. Chem., v.226, p.497-509, 1957.

FURUYA, W.M.; PEZZATO, L.E.; BARROS, M.M. et al. Tabelas brasileiras para a nutrição de tilápias. 2010. Disponível em: $<$ http://www.lisina.com.br/composicao.aspx $>$. Acessado em: 25 out. 2011.

HORWITZ, W.; LATIMER JUNIOR (Eds.). Official methods of analysis of AOAC International. 18.ed. Gaithersburg: AOAC International, 2006. 201p.

KANTACHOTE, D.; TORPEE, S.; UMSAKUL, $\mathrm{K}$. The potential use of anoxygenic phototrophic bacteria for treating latex rubber sheet wastewater. Electron. J. Biotechnol., v.8, p.314323,2005

KE， P.J.; CERVANTES, E.; ROBLESMARTINEZ, C. Determination of thiobarbituric acid reactive substances (TBARS) in fish tissue by an improved distillation-spectrophometric method. J. Sci. Food Agric., v.5, p.1248-1254, 1984.

KIRSCHNIK， P.G.; TRINDADE， M.A.; GOMIDE, C.A. et al. Estabilidade em armazenamento da carne de tilápia-do-nilo mecanicamente separada, lavada, adicionada de conservantes e congelada. Pesqui. Agropecu. Bras., v.48, p.935-942, 2013.

LAROSA, G. Desenvolvimento de produto cárneo de tilápia com antioxidantes naturais. 2011. 93f. Tese (Doutorado em Ciência de Alimentos) - Faculdade de Ciências Farmacêuticas, Universidade Estadual Paulista, Araraquara, SP.

MORAES, A.M.; SEIFFERT, W.Q.; TAVARES, F. et al. Desempenho zootécnico de tilápia do Nilo, Oreochromis niloticus, em tanques-rede, com diferentes rações comerciais. Rev. Ciênc. Agron., v.40, p.388-395, 2009.

OLIVEIRA, P.J. Licopeno no bem-estar de juvenis de tilápia do Nilo (Oreochromis niloticus): efeitos sobre desempenho e parâmetros químicos. 2009. 103f. Tese (Doutorado em Zootecnia) - Faculdade de Zootecnia e Engenharia de Alimentos, Universidade de São Paulo, Pirassununga, SP.
OTANI, F.S. Influência da adição in vivo de vitamina $E$ e de métodos de abate nos atributos de qualidade de filés de tilápia. 2009. 60f. Dissertação (Mestrado em Aquicultura) - Centro de Aquicultura, Universidade Estadual Paulista, Jaboticabal, SP.

PONSANO, E.H.G.; PINTO, M.F.; GARCIA NETO, M.; LACAVA, P.M. Evaluation of Rhodocyclus gelatinosus biomass for broiler pigmentation. J. Appl. Poult. Res., v.11, p.77-82, 2002.

REGULAMENTO da inspeção industrial e sanitária de produtos de origem animal. Brasília, DF: MAPA, 1952.

RIBEIRO, S.C.A.; RIBEIRO, C.F.A.; PARK, K.J. et al. Alteração da cor da carne de mapará (Hypophthalmus edentatus) desidratada osmoticamente e seca. Rev. Bras. Prod. Agroind., v.9, p.125-135, 2007.

RODRÍGUEZ, A.; LOSADA, V.; LARRAÍN, M.A. et al. Development of lipid changes related to quality loss during the frozen storage of farmed coho salmon (Oncorhynchus kisutch). J. Am. Oil Chem. Soc., v.84, p.727-734, 2007.

SANTO, E.F.E.; LIMA, L.K.F.; TORRES, A.P.C. et al. Comparison between freeze and spray drying to obtain powder Rubrivivax gelatinosus biomass. Food Sci. Technol., v.33, p.47-51, 2013.

SANTOS, E.C.B. Métodos de abate e qualidade da tilápia do nilo. 2013. 100f. Tese (Doutorado em Aquicultura) - Centro de Aquicultura, Universidade Estadual Paulista, Jaboticabal, SP.

SANTOS, V.G.; FERNANDES JUNIOR, A.C.; KOCH, J.F.A et al. Desempenho produtivo da tilápia-do-nilo arraçoada com dieta contendo farelo de nabo forrageiro. Bol. Inst. Pesca, v.35, p.451-459, 2009.

SAS/STAT 9.3 user's guide. Cary, NC: SAS Institute, 2011.

SASIKALA, C.; RAMANA, C.V.; CHALAM, A.V. et al. A survey of purple non-sulfur anoxygenic phototrophic bacteria associated with some industrial effluents. Indian J. Exp. Biol., v.33, p.136-138, 1995. 
SILVA, R.D.; ROCHA, L.O.; FORTES, B.D.A. et al. Parâmetros hematológicos e bioquímicos da tilápia-do-Nilo (Oreochromis niloticus L.) sob estresse por exposição ao ar. Pesqui. Vet. Bras., v.32, supl. 1, p.99-107, 2012.

SOUZA, M.L.R.; VIEGAS, E.M.M.; SOBRAL, P.J.A. et al. Efeito do peso de tilápia do nilo (Oreochromis niloticus) sobre o rendimento e a qualidade de seus filés defumados com e sem pele. Ciênc. Tecnol. Aliment., v.25, p.51-59, 2005.

SUSSEL, F.R. Tilapicultura no Brasil e entraves na produção. 2013. Disponível em: $<$ ftp://ftp.sp.gov.br/ftppesca/TilapiculturaEntrave s2013.pdf>. Acessado em: 19 maio 2014.

TABATA, Y. Soluções para agregar valor à truta salmonada. Case de sucesso. FUNDEPAG \& Negócios, v.1, p.22-24, 2007.

TAVARES-DIAS, M.; MORAES, F.R. Hematologia de peixes teleósteos. Ribeirão Preto: M. Tavares-Dias, 2004. 144p.
THE STATE of world fisheries and aquaculture. [s.1.]: FAO, 2014. Disponível em: $<$ http://www.fao.org/3/a-i3720e.pdf $>$. Acessado em: 04 set. 2014.

VALDUGA, E.; TATSCH, P.O.; TIGGEMANN, L. et al. Produção de carotenóides: microrganismos como fonte de pigmentos naturais. Quím. Nova, v.32, p.2429-2436, 2009.

VYNCK, W. Direct determination of the thiobarbituric acid value in trichloracetic acid extracts of fish as a measure of oxidative rancidity. Eur. J. Lipid Sci. Technol., v.72, p.1084-1087, 1970.

WANG, Y.J.; CHIEN, Y.H.; PAN, C.H. Effects of dietary supplementation of carotenoids on survival, growth, pigmentation, and antioxidant capacity of characins, Hyphessobrycon callistus. Aquaculture, v.261, p.641-648, 2006. 